\title{
Activismo estadounidense en la historia de la salud internacional
}

\section{United States' activism in the history of international health care}

\author{
Marcos Cueto \\ Pesquisador, Casa de Oswaldo Cruz/Fundação Oswaldo Cruz. \\ cuemarcos@gmail.com
}

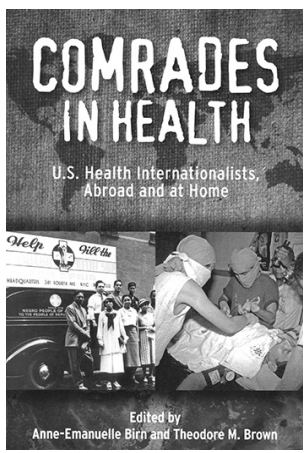

BIRN, Anne-Emanuelle; BROWN, Theodore M. Comrades in health: U.S. health internationalists, abroad and at home. New Brunswick: Rutgers University Press. 2013. $350 \mathrm{p}$.
T a historia de los médicos progresistas se asocia, generalmente, Lcon doctores europeos de los siglos XIX y XX. Sin embargo, el anarquismo, el socialismo, el marxismo, el comunismo y la medicina social europea tuvieron influencia entre los profesionales de salud de varios países de las Américas. Este trabajo es una valiosa contribución al conocimiento e interpretación de esta influencia en los EEUU. Es un tema de especial relevancia para los lectores interesados en conocer los antecedentes, la recreación y el impacto de tradiciones en salud pública y en la medicina que priorizaron la reforma social. Estos programas se diferenciaron de las propuestas sanitarias reduccionistas que sobre-enfatizaron la tecnología. Aunque los historiadores pueden encontrar muchos datos y perspectivas relevantes para su trabajo, este libro está dirigido a un público más amplio que incluye a líderes y trabajadores de salud.

En los primeros capítulos los editores presentan un resumen claro y profundo tanto de la medicina social europea como del internacionalismo socialista. Los editores sugieren tres características comunes en los activistas médicos estadounidenses: la lucha por la justicia social y la igualdad, la convicción de que era necesario modificar el orden económico y político para mejorar sustancialmente la salud de la población, y el internacionalismo o la solidaridad transnacional con los más pobres de los países en desarrollo.

Los trabajos del libro están reunidos en cuatro grupos generacionales (la generación nacida entre 1870 y 1910; entre 1920 y 1930; entre 1940 y 1960; y entre 1960 y 1970). De esta manera, las generaciones y sus contextos son la estructura que los editores le han dado al libro. Sobre la primera generación, se presentan estudios históricos originales. Entre ellos destacan el que realiza Susan Gross Solomon sobre la influencia de la medicina soviética en los EEUU de la década de 1930, el capítulo de Walter J. Lear sobre la participación de médicos, enfermeras y otros profesionales de salud en la Brigada Abraham Lincoln que 
combatió por la república durante la Guerra Civil Española y el trabajo elaborado por Jane Pacht Brickman sobre el impacto del Macartismo en la persecución de médicos progresistas durante la Guerra Fría (entre las víctimas estuvo Henry Sigerist, el fundador de la historia de la medicina moderna en los EEUU, quien simpatizaba con el sistema médico de la URSS). Los primeros capítulos ayudan a comprender por qué la conservadora medicina oficial y los gobiernos norteamericanos se resistieron a sistemas universales de salud como los que empezaron a surgir en Europa con la construcción del Estado de Bienestar.

La mayoría de los capítulos son testimonios fascinantes de actores clave del activismo medico progresista de los EEUU en diferentes contextos y revoluciones que ocurrieron en Cuba, China, Mozambique, Chile y en otros países del mundo. Los médicos estadounidenses realizaron contribuciones fundamentales, a veces como activistas y en otras como académicos, a nuevas preocupaciones socio-médicas como la lucha por los derechos civiles de las minorías étnicas discriminadas, la implementación comunitaria de la atención primaria de salud, la promoción de la igualdad de género, la promoción de la paz, la estrecha vinculación entre inequidad social y malas condiciones de salud y la defensa de la salud como uno de los derechos humanos fundamentales de cualquier ciudadano. El libro concluye con algunos rasgos en común del internacionalismo sanitario de los EEUU como que existió una transmisión de ideas y experiencias entre los miembros de las diferentes generaciones, la oposición a las políticas oficiales del gobierno estadounidense (y generalmente a varias agencias multilaterales y donantes privados), la conciencia del riesgo personal y profesional que muchos de ellos corrieron por causa de sus ideas, la crítica radical al orden social existente y el descubrimiento que en su propio país - es decir en los EEUU - existía población pobre y marginada que era similar a la de los países en desarrollo. Otra característica que sugieren los editores es que el activismo progresista cuestionó una definición simplista de la "pobreza" como la causa de la enfermedad - lo que hacen, desde hace unos años, muchas agencias internacionales y fundaciones - porque a veces puede servir para culpabilizar a las víctimas o pensar que el trabajo sanitario internacional es solamente un acto de caridad de los ricos hacia los necesitados. Para ellos, una lucha frontal y decidida contra la pobreza implica modificar drásticamente el orden político y económico existente que sustenta la reproducción de la miseria y la enfermedad.

Según los editores, la medicina social latinoamericana - que tuvo entre sus líderes al médico chileno Salvador Allende - es una de las tradiciones más fuertes de una perspectiva progresista en favor del cambio social y sanitario. De acuerdo. Sin embargo, considero anacrónico ubicar a Eduardo Espejo, el medico ecuatoriano del periodo colonial tardío, como un exponente de esta tradición. Asimismo, es debatible la explícita exclusión que hacen los editores de la ONG Socios en Salud, que dirige Paul Farmer, y que tiene cuarteles generales en la ciudad de Boston pero trabaja activamente en las zonas más pobres de Haití, Perú y otros países del mundo. Según las conclusiones de este libro, a pesar de una crítica a los determinantes de la salud, esta ONG tiene pocos lazos con movimientos izquierdistas que se enfrenten radicalmente al poder económico.

Los editores de este libro revelan con franqueza que son un testimonio de parte. Es decir, que tienen una clara simpatía con la mayoría de los personajes que analizan. Probablemente, la mayoría de los trabajadores e historiadores de la salud tengan la misma simpatía y adhieran 
con las ideas igualitarias que emanan de esta tradición y de trayectorias profesionales y personales ejemplares. Sin embargo, eso no excluye la necesidad que en el futuro se elaboren trabajos de investigación que sean inquisitivos y expliquen no solo los logros sino también las limitaciones de esta tradición que iba contra la hegemonía de la medicina oficial. Entre estas limitaciones creo que estuvieron la falta de crítica a la rigidez y al autoritarismo del modelo de sociedad de la URSS y la inhabilidad de formar amplias coaliciones sociales por el cambio social. Es, de todos modos, un libro inspirador que permite conocer la historia de los médicos progresistas en las Américas.

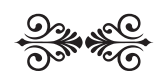

